\title{
Electric Power Steering System for Agricultural Truck Matching Design
}

\author{
Z.G. Chen \\ Mechanical and energy engineering department \\ Shaoyang University \\ Shaoyang, Hunan, China \\ W. Zhang \\ Mechanical and energy engineering department \\ Shaoyang University \\ Shaoyang, Hunan, China
}

\author{
Q. Zhang \\ Mechanical and energy engineering department \\ Shaoyang University \\ Shaoyang, Hunan, China \\ T.M. Zhou \\ Zhuzhou Elite Electro Mechanical Co, Ltd \\ Zhuzhou, Hunan, China
}

\begin{abstract}
-this thesis aimed at the characteristics and the structural of a type of truck. It confirmed that its chosen power-assisted form of electric power steering system is Column EPS - that is C-EPS. On the platform of a sort of car we combined with the technical requirements of a certain model car steering system performance upgrades and matched design of the motor, the decelerating device, and the transducer. Finally device of the EPS in a certain automobile model truck for the characteristics test of input and output, it have shown that the EPS has a good matching design of the booster effect.
\end{abstract}

Keywords-EPS; matching; design; test

\section{INTRODUCTION}

With the development of products of the automotive industry, energy efficiency and environmental protection will become a trend automotive electric power steering system( Electric Power Steering, referred to as EPS ) is the first choice for every large automobile company both at home and abroad due to its advantage of well assist characteristic, fuel economy, good low-temperature running, compact structure, and easy assembly. This thesis aimed at the characteristics and the structural of a type of car. It confirmed that its chosen power-assisted form of electric power steering system is Column EPS - that is C-EPS. In order to make sure that electric power steering possesses better handle, lower noise, and higher reliability, we combined with the technical requirements of a certain model car steering system performance upgrades and matched design of the motor, the decelerating device, and the transducer. Finally we have run testes device of the EPS in a certain automobile model car for the characteristics of input and output.

\section{SYSTEM AND OPERATING PRINCIPLES OF EPS}

EPS system mainly includes assisted motor, torque sensor, decelerating device, and controller (ECU).Its structures are shown following Figure 1.

Operating principles: EPS was in a working state after auto engine started. Torque sensor will detect the torque and angle size what for the rotation in the steering wheel as soon as driver manipulate and rotate the steering wheel. At the same time, torque sensor will receive signals of engine speed and vehicle speed. Then it will transform into digital signal and input control unit. After that it calculate we will get and make driving cycle so good at adapting assisting torque. Next, controlling assisted motor, outputting the corresponding size and direction, increasing torque by the decelerating device, it finally applied to the gear and rack so that it perform power-assisted steering[1].

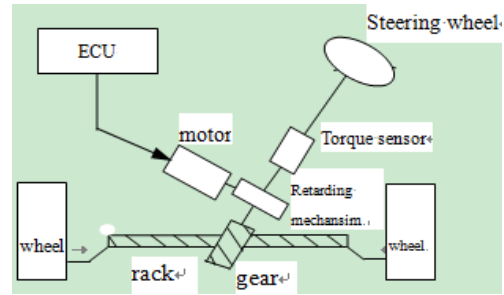

FIGURE I. THE SYSTEM ST RUCTURE DIAGRAM OF EPS.

\section{THE MATCHING DESIGNS OF THE MOTOR OF EPS AND THE RET ARDING MECHANISM} 1.

The parameters of the entire car one type of car, see Table

TABLEI. THEPARAMETERS OF THE ENTIRE CAR.

\begin{tabular}{|l|l|l|l|}
\hline No & \multicolumn{1}{|c|}{ Project } & Code & Parameter \\
\hline 1 & Full mass(kg) & $\mathrm{m}$ & 3500 \\
\hline 2 & Steering gear angle ratio & $\mathrm{I}$ & 17.2 \\
\hline 3 & $\begin{array}{l}\text { Number of turns about the steering } \\
\text { wheel(collar) }\end{array}$ & $\mathrm{n}$ & $2.9-3.3$ \\
\hline 4 & $\pi$ & $\pi$ & 3.1416 \\
\hline 5 & Sliding friction & $\mathrm{f}$ & 0.70 \\
\hline 6 & $\begin{array}{l}\text { The max rotato speed of steering } \\
\text { wheel(r/min) }\end{array}$ & $\mathrm{W}_{\mathrm{h}}$ & 75 \\
\hline 7 & $\begin{array}{l}\text { Ldeal situ steering wheel torque } \\
(\mathrm{N} \cdot \mathrm{m})\end{array}$ & $\mathrm{M}_{\mathrm{h} 0}$ & 5.50 \\
\hline 8 & $\begin{array}{l}\text { Transmission efficiency of wrom and } \\
\text { gear mechanism }\end{array}$ & $\eta_{0}$ & 0.80 \\
\hline 9 & Pressure of the wheel(MPa) & $\mathrm{P}_{0}$ & 0.22 \\
\hline 10 & Front axle load(Kg) & $\mathrm{G}_{1}$ & 820 \\
\hline
\end{tabular}


According to the load state of a type of farm vehicle and the calculation on relative parameters and the space size of vehicle itself, cab interior space becomes small. Space layout of the clutch pedal, the brake pedal and the accelerator pedal become small, too. To meet the needs of man-machine It is considered final what engineering, steering column is turned into form of assist. That is C-EPS structure. Motor is power source of EPS structure as instructions of ECU output suitable assisting torque. Electric machinery is key component of EPS structure. It has significant effect on performance of EPS structure. Electric machinery of C-EPS has many characteristics such as good working environment (cab's environment), little ripple of the torque, faint machinery vibration, low sealing require ment, low noise, low power, small size, low revs, connector no waterproof require ment, low require ment of surface protection, good heat dissipation surrounding, low machine-electro time constant, and so on [2].The role of decelerating device is amplification. of assisting motor output torque. Transmission of decelerating device fairly large. It requests that electrical machinery outputs lower torque and higher working speed. Meanwhile the size of decelerating device becomes very large. This lead to difficulty in spacial arrangement. Transmission ratio of decelerating device is so small that it requests the electrical machinery output higher torque and lower working speed. It makes the size of the electrical machinery increase and improves the requirement of electrical machine design. In order to facilitate machine and assemble, it mainly require higher transmission efficiency and smaller rotary inertia when the decelerating device select option. It also requires the size as small as possible. To act as the power component of the EPS system, electromechanical decelerating device is very important for matching the whole system.

\section{THE CHOICE OF TYPE ON THE DYNAMO ANDTHE DECELERATING DEVICE}

At present, the assisted machine of EPS system mainly consis ts of brush dc motor and brushless dc motor at ho me and abroad. The brush dc motor using the mechanical commutator for reversing, it needs to maintain carbon brush regularly. Its power density is low. The brushless dc motor adopts electronic commutation, no maintenance, high power density, but the cost is higher. Generally, choosing a brush dc motor that is a good idea for lower power-assisted cars. Choosing a brushless dc motor high car is suitable for higher power-assisted car. With mature techniques, simple controller and low cost, the brush dc motor are widely used in domestic electric power steering system.

EPS commonly used is worm and worm wheel type and planetary gear type about retarding mechanism. With high efficiency, when retarding mechanism of Worm and worm wheel type are arranged, it requires less space, stable and reliable. Retarding mechanism of planetary gear type is relatively complex. It can change transmission characteristics of the steering system's angle. Usually, choosing and matching the worm and worm wheel type retarding mechanism and steering-shaft-type power system, the requirements for smaller space collocation are met.
Considering the actual needs, in this essay, assisted motor chosen was brush dc motor. In the meantime, retarding mechanism chosen was worm and worm wheel type.

\section{V.PARAMETER DESIGN OF THE MOT OR OF EPS AND THE RET ARDING MECHANISM}

Because the motor act on ass isted torque $\mathrm{T}$ of sheering shaft which is influenced by many factors, $i$ (the speed reducing ratio of retarding mechanism), Km (electro magnetic torque constant of the motor), Ke (back electromotive force constant of the motor), w ( angular velocity of steering wheel) and so on. As the ratio of retarding mechanism increases, the steering wheel torque also increases[3].At the same time, response time of yaw velocity get longer,and phase lag rise. The relationship between them is as follows:

$$
\mathrm{T}_{\max }(\mathrm{w})=\mathrm{i} \mathrm{K}_{\mathrm{m}}\left(\mathrm{U}_{\mathrm{m}}-\mathrm{K}_{\mathrm{e}} \mathrm{iw}\right) / \mathrm{R}_{\mathrm{m}}
$$

Among them: $T \max (\mathrm{w})$ :the maximum assisted torque is acted on steering shaft by the electric machinery .Um: the voltage is added to two ends of motor circuit by power.

Increasing the reduction ratio will lead to reducing transmission efficiency of retarding mechanism It makes the effect of power assisting and returnability worsen. If the reduction ratio is too big, it will make its reverse efficiency is too low, even appear self-locking phenomena. At this rate, steering system wil lose the function of returnability. When the motor of EPS and retarding mechanism match, the motor of high torque constant and retarding mechanism of low reduction ratio will be chosen. For schneckenantrieb, its transmission ratio is generally from 15 to 20 . This essay choose 16.5 as reduction ratio.

According to the calculating motor the parameter of the front axle load:

Situ steering torque:

$$
\mathrm{Mr}=\mathrm{f}^{*}\left(\left(9.8^{*} \mathrm{G} 1\right) 3 / \mathrm{P} 0\right) 1 / 2 / 3000=360.1(\mathrm{~N} \cdot \mathrm{m})
$$

No power the steering wheel torque:

$$
\mathrm{Mh}=\mathrm{Mr} /\left(\eta^{*} \text { iw }\right)=27.9(\mathrm{~N} \cdot \mathrm{m})
$$

To the maximu m torque:

$$
\mathrm{Ma}=\mathrm{Mh}-\mathrm{Mh} 0=22.9(\mathrm{~N} \cdot \mathrm{m})
$$

Motor rated power:

$$
\mathrm{P}=2 \pi * \mathrm{Ma} * \mathrm{Wh} /(60 * \eta 0)=225(\mathrm{~W})
$$

Motor nom speed:

$$
\mathrm{n}=\mathrm{Wh} * \mathrm{i}=1023.75(\mathrm{r} / \mathrm{min})
$$

Motor rated torque:

$$
\mathrm{T}=60 * \mathrm{P} /(2 \pi * \mathrm{n})=1.94(\mathrm{~N} \cdot \mathrm{m})
$$


In accordance with the calculation consequence, Mitsubishi brush dc motor was chosen with motor nom speed was chosen $1050 \mathrm{r} / \mathrm{min}$, Motor rated power was chosen270W, and Motor rated torque $2.4 \mathrm{~N} . \mathrm{m}$.

\section{NONCONT ACTING PICKUP MATCHING DESIGN}

In electric power steering system, when driver control the steering wheel, torque sens or was used to measures the driner's the force of the hand, HW Hand-Wheel Angle, rotational speed and so on. Nevertheless, these informations are all ECU control signals. The accuracy of the information is very important for electric power steering system. Torque sensor is one of the key hardware electric power steering system.

Common torque sensor are mainly contact type and non-contact type torque sensor. Contact type torque sensor generally include swing arm torque sensor, dual planetary gear type torque sensor and torsion bar type torque sensor. Contact torque sensor cost is low, but easy to be resulted in temperature drift, short service life. Non-contact torque sensor includes optical torque sensor and magnetoelectric torque sensor. Compared with contact torque sensor, the non-contact torque sensor is high precision, good anti-jamming capability, but the cost is higher. The choice of torque sensor is usually should consider measurement accuracy, the cost, working environment, and service life[4].

EPS of a type of farm vehicle was used a new electromagnetic induction non-contact sensors. The sensor is wearproof, small hysteresis, small influence of follow-up attention outside factors. And it was solved the problem of the sensor potential with the temperature drift [5]. Non-contact sensor structure is shown in Figure 2.

Sensor characteristics shall meet the following requirements: the main line, output the corsspoint of au xiliary road---that is the initial work location 0 , (that is, middle position of the effective electrical Angle).When Working voltage is $+5 \pm 0.05 \mathrm{~V},+12 \pm 0.12 \mathrm{~V}$, the voltage of the main line and the auxiliary road should be $2.5 \pm 0.05 \mathrm{~V}$. Any other location shall meet Vmain line+Vauxiliary $\operatorname{road}=5 \mathrm{~V} \pm 0.15 \mathrm{~V}$.And it require $0.8 \mathrm{~V} \leq$ Vmain $\operatorname{limit} \leq 4.2 \mathrm{~V}, \quad 0.8 \mathrm{~V} \leq$ Vauxiliary limit $\leq 4.2 \mathrm{~V}$. Figure 3 meet the requirements for non-contact sensor in the characteristics of a type in the actual test.

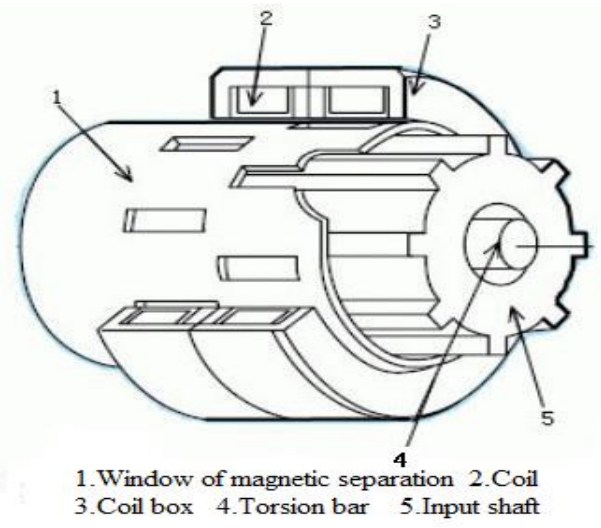

FIGURE II. MECHANICAL ST RUCTURE OF THE SENSOR.

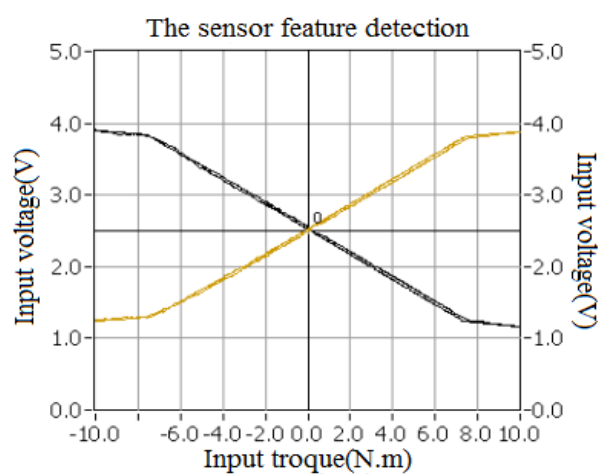

FIGURE III. THE SENSOR CHARACTERISTIC

\section{THE TEST ON EPS OF INPUT -OUTPUT CHARACTERISTICS}

The matching design of EPS after input/output characteristic test, the test tools include EPS controller, torque sensor, Angle sensor, data acquisition system, computer, inverter and so on. To test under different speeds, the input and output torque/force curve that is whether the input and output characteristics comply with the design requirements and whether the curve of different vehicle speeds has good symmetry. To set the device installed on a test rack and different speed, with $20 \mathrm{r} / \mathrm{min} \sim 30 \mathrm{r} / \mathrm{min}$ speed uniform rotation of input shaft, we record the speed of input and output torque moment/force curve. The test results as shown in Figure 4, $0 \sim 80 \mathrm{~km} / \mathrm{h}$ input/output characteristic curve. Figure illustrates the input of $2 \mathrm{Nm}$, situ output is $4 \mathrm{Nm}, \quad 20 \mathrm{Km} / \mathrm{s}$.Output is 1 $\mathrm{Nm}, 40 \sim 80 \mathrm{~km} / \mathrm{s}$ input is 0.8 . Input is $3 \mathrm{Nm}$, in situ output is $6.2 \mathrm{~N} / \mathrm{m}, 20 \mathrm{~km} / \mathrm{s}$ output for $4 \mathrm{Nm}, 40 \mathrm{~km} / \mathrm{s}$ output to $2 \mathrm{Nm}, 60$ $\mathrm{km} / \mathrm{s}$ output is $1.5 \mathrm{Nm}$, and $80 \mathrm{~km} / \mathrm{s}$ output is $1 \mathrm{Nm}$. At low speeds, power is larger. Assisting power should weaken as the speed increase. It is easy to see after the design of EPS matches, it meet the power demand. It can make the vehicle has good steering portability and sensitiveness, too. Besides, it has a good handle and driving stability at high speeds [6].

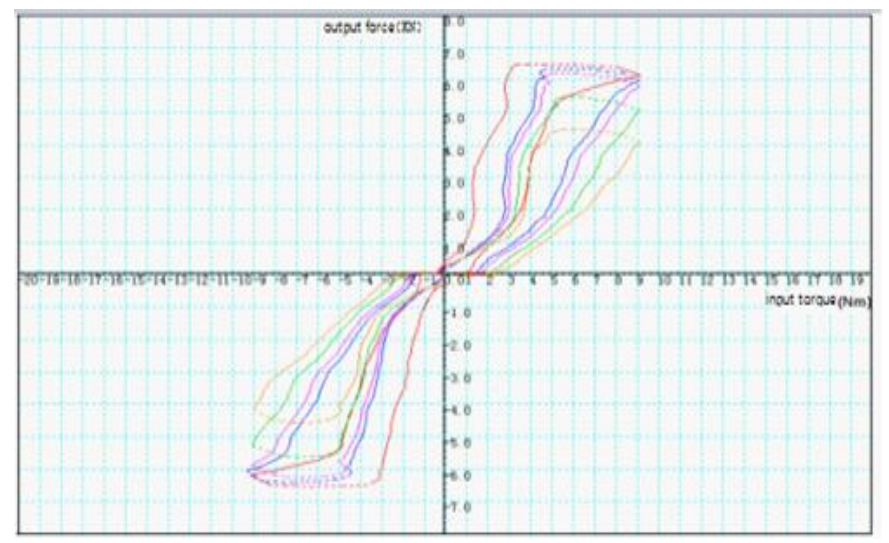

FIGURE IV. INPUT AND OUTPUT CHARACTER CURVE.

\section{CONCLUDING REMARKS}

Based on the analysis and calculation of vechicle parameter of a type of agricultural truck, a type of agricultural truck was matched and designed. After matched, EPS was done input/output characteristic test. The results show that EPS system can achieve good effect of power. Meanwhile, it has 
the advantage of good steering portability, sensitiveness, handle and driving stability.

\section{ACKNOWLEDGEMENTS}

This research was financially supported by Hunan Province University Innovation Platform Development Foundation (Grant No.13K109) and Research Innovation Projects of Shaoyang University graduate (CX2013S Y026)

\section{REFERENCE}

[1] ZHOU Tingming, LIU Zhihui, LI Mengqi, CHEN Zhigang, TANG Ning. Electronic Power Steering System and Its Key Technologies [J]. Hydromechat ronics Engineering, 2012，40(7):176-179, 209.

[2] XIANG jinquan. Motor Matching Technologies of Automotive Electric Power Steering System[J]. Aut omobile Parts, 2013(02):58-61, 64.

[3] Kong Fansheng. Study on Eleetric Power Steering System Matching with Xiali Passenger Vehiele[D]. Journal of Jilin University Engineering and Technology Edition.2010.

[4] Liu Cai. Electronic Power Steering Matching Design on a Mini-van [D]. Journal of Hunan University.2013.

[5] Yang Guangchuan.Discussion on EPS sensor of the median voltage Key points of design and development [J]. Mechanical and electrical Technology.2013 (01):48-50.

[6] XIANG Dan, LI Wu-bo, YANG Yong. Study on Return-to-center Control and Simulation for Electric Power Steering System [J]. Machinery Design \& Manufacture .2012(08). 